\title{
SPARTICUS: Small Particles in Cirrus Science and Operations Plan
}

\author{
J Mace \\ Principal Investigator \\ E Jensen D Mitchell \\ G McFarquhar X Liu \\ J Comstock T Garrett \\ T Ackerman
}

October 2009 


\section{DISCLAIMER}

This report was prepared as an account of work sponsored by the U.S. Government. Neither the United States nor any agency thereof, nor any of their employees, makes any warranty, express or implied, or assumes any legal liability or responsibility for the accuracy, completeness, or usefulness of any information, apparatus, product, or process disclosed, or represents that its use would not infringe privately owned rights. Reference herein to any specific commercial product, process, or service by trade name, trademark, manufacturer, or otherwise, does not necessarily constitute or imply its endorsement, recommendation, or favoring by the U.S. Government or any agency thereof. The views and opinions of authors expressed herein do not necessarily state or reflect those of the U.S. Government or any agency thereof. 


\section{SPARTICUS: Small Particles in Cirrus Science and Operations Plan}

J Mace, University of Utah

Principal Investigator

E Jensen, NASA Ames

G McFarquhar, University of Illinois

J Comstock, Pacific Northwest National Laboratory

T Ackerman, University of Washington

D Mitchell, Desert Research Institute

X Liu, Pacific Northwest National Laboratory

T Garrett, University of Utah

October 2009

Work supported by the U.S. Department of Energy,

Office of Science, Office of Biological and Environmental Research 


\section{Contents}

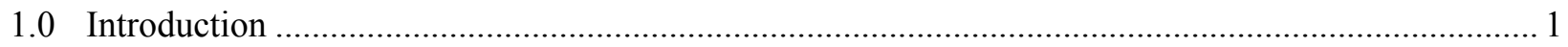

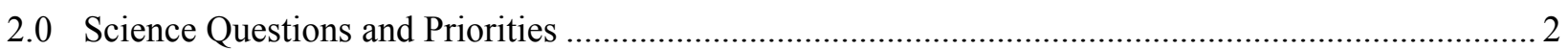

3.0 Assets 3

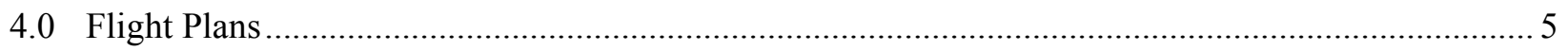

4.1 Experimental Objective 1: Small Particles in Cirrus............................................................... 6

4.2 Experimental Objective 2: Ground-based Remote Sensing Validation ................................... 7

4.3 Experimental Objective 3: Cloudsat, CALIPSO, MODIS Validation ..................................... 8

4.4 Experimental Objective 4: Cirrus Evolution .......................................................................... 9

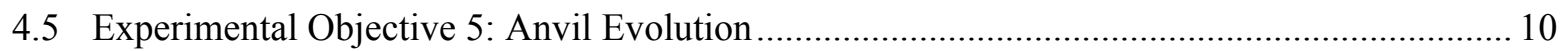

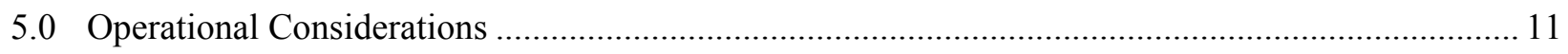

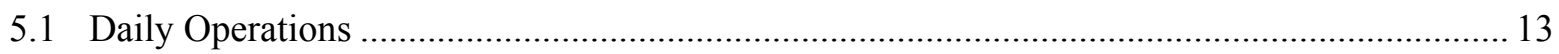

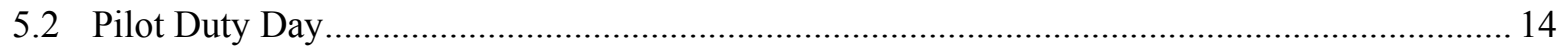

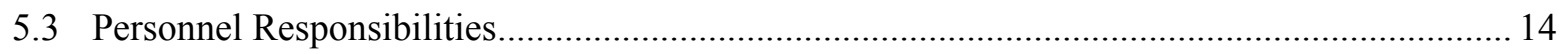

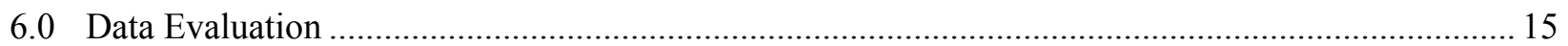

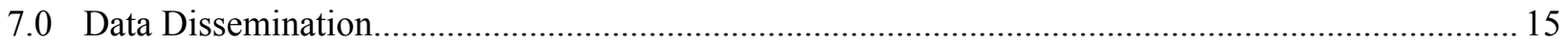




\section{Figures}

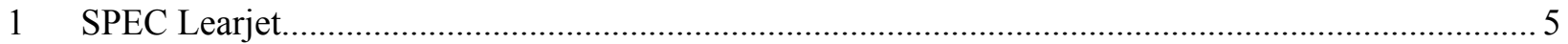

2 Flight operations area includes two 400-nautical-mile circles centered around Boulder, Colorado, and the ARM SGP site near Lamont, Oklahoma. ....................................................... 12

\section{Tables}

1 Instruments to be installed on the SPEC Learjet for SPARTICUS. ............................................ 4

2 SPEC Learjet operating characteristics when in research configuration. ......................................... 6

3 Sample flight day for typical cirrus flight plan over the SGP site. All times are in Mountain

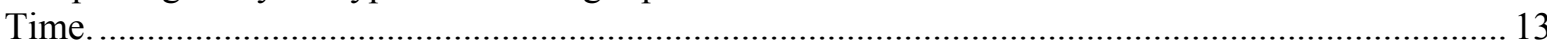




\subsection{Introduction}

From a mass-weighted perspective, cirrus clouds exert an enormous influence on the radiative energy budget of the earth's climate system. Owing to their location in the cold upper troposphere, cirrus can significantly reduce the outgoing longwave radiation while, at the same time, remaining relatively transmissive to solar energy. Thus, cirrus clouds are the only cloud genre that can exert a direct radiative warming influence on the climate system (Ackerman et al. 1988). It is not surprising, therefore, that general circulation models (GCMs) are especially sensitive to the presence of cirrus in the model atmosphere. Lohmann and Roeckner (1995), for instance, show that the climate sensitivity can vary by as much as $40 \%$ due to the properties of cirrus varying between transparent and opaque limits. Lohmann and Roeckner (1995) also identify a key feedback by cirrus that is often overlooked; on longer time scales cloud heating in the upper troposphere can act to maintain and modulate the general circulation of the atmosphere through accelerating the subtropical and polar jet streams. Understanding these mechanisms and representing them in models is complicated by the fact that cirrus properties vary over an enormous dynamic range compared to most other clouds.

The cirrus feedbacks are most easily understood in the tropics where the mean atmosphere is in approximate radiative-convective equilibrium and cirrus-induced heating can influence the lapse rate and, thereby, help to modulate convection (Mather et al. 2007). However, the heating of the upper troposphere in the mid-latitudes by cirrus (Mace et al. 2006, 2008) also feeds back directly on the large-scale circulation, causing, for instance, an acceleration of the subtropical jets (Ramanathan 1983; Slingo and Slingo 1988). The role of cirrus in climate feedbacks can be understood by considering the cirrus impact on climate sensitivity (i.e., the equilibrium response of global-mean surface temperature to $\mathrm{CO}_{2}$ doubling). Sanderson et al. (2008) examined an ensemble of thousands of "perturbed physics" GCM simulations and found that the cumulus entrainment coefficient, which controls the amount of moistureladen boundary layer air that is vertically advected into the upper troposphere in deep convection, and the ice fall speed, which controls ice removal rates from cirrus, have the largest impact on climate feedbacks. This study indicates that climate sensitivity depends more on changes in cirrus clouds than on, for instance, changes to low-level boundary layer clouds. These conclusions are further supported by conventional GCM studies (Mitchell et al. 2008) and global studies using the Multi-scale Modeling Framework or "superparameterization" approach (Randal et al. 2003).

As the next generation of parameterizations for cirrus clouds in GCMs becomes available (e.g., Tompkins et al. 2007; Liu et al. 2007), the veracity of these parameterizations hinges critically on available observations. The long-term measurements that ARM has collected over the last decade capture much of the detail needed to improve and evaluate cirrus parameterizations. However, interpreting the ARM data for this purpose relies on a basic conceptual understanding of cirrus microphysical properties and its formation, maintenance, and dissipation processes that can only be acquired with in situ aircraft measurements. Earlier in situ data sets of cirrus microphysical properties have large uncertainties associated with the presence of small particles (maximum dimensions $\mathrm{D}<50 \mu \mathrm{m}$ ). This gap in reliable information hampers evaluation of cirrus physical processes, hinders validation of remote sensing retrievals, and thereby limits our ability to develop realistic cirrus parameterizations for GCMs. 


\subsection{Science Questions and Priorities}

Given the importance of cirrus cloud feedbacks to our climate system, accurate statistics concerning cirrus microphysical properties and associated environmental conditions are needed. Our motivation for this extended aircraft-based field campaign is centered on the following three science questions:

- What is the nature and variability of the particle size distribution in cirrus?

- Given the uncertainty in previous measurements, to what degree do small particles (i.e., $<50 \mu \mathrm{m}$ diameter) contribute to the mass and radiative properties of mid-latitude cirrus? Characterization of the contribution of small particles to the total number concentration is critical for developing and evaluating model parameterizations and improving algorithms to retrieve microphysical properties using remote sensors.

- How do cloud-scale dynamical processes control the evolution of cirrus properties through nucleation, particle growth, and sublimation?

- Putting the microphysical processes into context with cloud-scale to large-scale dynamic and thermodynamic conditions will advance our understanding of the nucleation process and further enhance parameterization development.

- What degree of complexity is required in cloud property retrieval algorithms, and what minimal set of algorithms can be used to rigorously describe cirrus microphysical properties using ground-based ARM Climate Research Facility (ARM Facility) data?

- SPARTICUS measurements will reshape our understanding of the bimodality of the ice crystal size distribution. Improving and evaluating cloud property retrieval algorithms is fundamental to utilizing the long-term time record of remote sensing observations at the ARM Facility sites.

The persistent theme of this experiment is quantifying processes that control concentrations of small particles in cirrus. Because of the uncertainty regarding the role that shattering of large ice crystals may have played in artificially amplifying these concentrations in past data sets, questions about small crystal prevalence persist in the cirrus community, hindering our ability to answer these questions. SPARTICUS intends to provide these answers through a five-month campaign of aircraft measurements in cirrus.

Cirrus clouds are complex in terms of dynamical forcing, crystal nucleation and growth, and dissipation. Due to this complexity, aircraft measurements alone are often insufficient to answer the basic science questions. They become much more useful when placed in the context of meteorological and remote sensing measurements. The combined measurement set becomes more powerful by the sampling of multiple events, allowing the research community to draw both physical and statistical inferences. The goal of SPARTICUS is to create this extended set of measurements. Thus, the highest priorities for measurements are those that provide the greatest intersection with remote sensing measurements and a diversity of meteorological conditions.

\section{Priority 1: The ARM Southern Great Plains Site}

The highest priority for aircraft measurements is over the ARM SGP site. The continuously operating millimeter-wavelength radar (MMCR) and Raman lidar, as well as the suite of radiometers, radiosondes, and other instruments, provide the remote sensing context for the aircraft. In addition, the simultaneous 
acquisition of remote sensing and in situ measurements allows for the evaluation and continued refinement of retrieval algorithms. The primary objective is to obtain cirrus size distribution information over the SGP remote sensors. This dictates flight patterns consisting of short horizontal legs and spirals over the ARM SGP site. Our evaluation of MMCR data over a five-year period shows that cirrus are present over the SGP site between 140 and 230 hours per month from October to March. Since our flight time is approximately 40 hours a month, this should allow us plenty of opportunities to identify cirrus targets for aircraft flights. We expect to devote approximately $60 \%$ of our flight hours (120 hours) to the SGP targets.

\section{Priority 2: Under-flying the NASA A-Train}

The NASA A-Train satellite constellation includes a millimeter-wavelength radar (CloudSat) and a backscatter lidar (CALIPSO), as well as various passive radiometers. Our second priority is to under-fly the A-Train. The primary objective is to obtain cirrus size distribution data in conjunction with sampling by the remote sensing instruments. This dictates flights that have somewhat longer horizontal legs and place less emphasis on spirals. We expect to devote approximately $20 \%$ of our flight hours (40 hours) to under-flying the A-Train. Assuming that each under-flight consumes 3-4 flight hours, this would permit 10 to 11 under-flights, or about 2 per month. Given the need to fly in cirrus exactly under the A-Train constellation and the logistical constraints of the aircraft, this is a workable number; it is unlikely that we could fly many more A-Train paths.

\section{Priority 3: Other cirrus}

One of our goals is to fly in a broad range of cirrus clouds. The constraints of needing cirrus over the SGP site or under the A-Train will undoubtedly lead to a situation where we have difficulty sampling a particular type of cirrus in either configuration. In addition, there may be days when the cirrus moves off one of our targets after the plane is launched. These situations lead us to sample cirrus as targets of opportunity. Our goal is to keep this sampling to a minimum, but it is unavoidable. We expect to devote approximately $15 \%$ of our flight hours (30 hours) to these cirrus.

\subsection{Assets}

The SPARTICUS instrument suite is designed for routine observations of cirrus ice-water cloud properties. Gathering representative statistics of cirrus microphysical properties is a major goal for SPARTICUS, so the aircraft payload was kept as simple as possible to enable the cost effectiveness needed for routine observations, but at the same time, kept as complete as possible to get the required confidence in the robustness of the observations. Following the experience gained during the routine observations of liquid-water clouds during RACORO, an attempt was made to select probes that had a track record of reliability, required minimal maintenance, and had relatively routine processing by automated means. Some newer probes that would be desired for redundancy and were representative of newer technological advances were not included in the payload because they would require more attention than possible in a long-term routine observational program and because there was a limit to the number of instruments that the SPEC Learjet could hold. However, all probes require maintenance and calibration, so the necessary personnel and resources for ensuring data quality and archiving the data were required in the budget. 
Table 1 summarizes the probes to be used for SPARTICUS. Of paramount importance for SPARTICUS is determining the concentrations of small ice crystals, hereafter those with maximum dimensions (D) less than $50 \mu \mathrm{m}$. Because of this, both a Cloud Droplet Probe (CDP) and a fast Forward Scattering Spectrometer Probe (FSSP) are included in the payload for measuring small crystals. The CDP, with no shroud and inlet, should not suffer from artificial amplification of small ice crystals due to shattering of large ice crystals on protruding elements of other forward scattering probes. The fast FSSP is critical because it provides information on the inter-arrival times between particles, information that can be used to remove artifacts caused by shattering from the data. The two-D stereo probe (2DS), with its lower detection limit of $10 \mu \mathrm{m}$, can be compared against data from the fast-FSSP and CDP to help assess any degree of shattering. The $2 \mathrm{DS}$, measuring $10<\mathrm{D}<3000 \mu \mathrm{m}$, is also critical for quantifying concentrations of cloud particles. The two-dimensional precipitation (2DP) probe measures sizes between 2 and $6400 \mu \mathrm{m}$ and is critical for measuring the larger precipitation particles. Information about particle habit will be obtained from high-resolution $(2.3 \mu \mathrm{m})$ images of ice crystals obtained by the U.S. DOE Cloud Particle Imager (CPI), which will also be used to generate size distributions for comparison against the 2DS using the calibration recently obtained at the University of Manchester. Estimates of bulk ice water content, crucial for inter-comparisons against estimates derived from the size-resolved probes in closure tests, will be obtained from a deep-cone Nevzorov probe. Aerosol size distributions will be measured by a PCASP probe, turbulence from an AIMMS-20, and humidity from a diode laser hygrometer (DLH) supplied by NASA Langley. The atmospheric and aircraft state parameters will be derived from the AIMMS-20 and a Rosemount probe. The mentor for all the aforementioned probes is SPEC (Lawson), with the exception of the humidity measurements that will be mentored by NASA (Diskin).

All of the aforementioned probes will be installed on the SPEC Learjet, depicted in Figure 1. The Learjet will fly 200 hours in support of the SPARTICUS objectives from 15 November 2009 to 15 April 2010. Table 2 summarizes the performance characteristics of the SPEC Learjet when used in a research configuration.

Table 1. Instruments to be installed on the SPEC Learjet for SPARTICUS.

\begin{tabular}{|l|l|c|c|l|}
\hline \multicolumn{1}{|c|}{ Measurement } & \multicolumn{1}{|c|}{ Instrument } & Provider & Mentor & \multicolumn{1}{c|}{ Location } \\
\hline SD 2-50 mm & Cloud Droplet Probe (CDP) & $\begin{array}{c}\text { AAF } \\
\text { (DMT) }\end{array}$ & SPEC & Starboard Tiptank \\
\hline SD 1-50 mm & $\begin{array}{l}\text { Fast Forward Scattering } \\
\text { Spectrometer Probe (FSSP) }\end{array}$ & SPEC & SPEC & Port Belly Pylon \\
\hline SD 10-3000 mm & 2D Stereo Probe (2DS) & SPEC & SPEC & Starboard Belly Pylon \\
\hline SD 200-6400 mm & $\begin{array}{l}\text { Two-Dimensional } \\
\text { Precipitation Probe (2DP) }\end{array}$ & SPEC & SPEC & Port Tiptank \\
\hline SD 0.1-3.0 mm & PCASP & AAF & SPEC & Alternate with 2DP \\
\hline Ice habit, SD & Cloud Particle Imager (CPI) & AAF & SPEC & Center line Belly Pylon \\
\hline Ice Water Content & Deep-Cone Nevzorov & SPEC & SPEC & Nose \\
\hline Turbulence & AlMMS-20 & SPEC & SPEC & Starboard Tiptank \\
\hline $\begin{array}{l}\text { Atmospheric and } \\
\text { Aircraft State } \\
\text { Parameters }\end{array}$ & Rosemount and AIMMS-20 & SPEC & SPEC & $\begin{array}{l}\text { Nose (Rosemount) and } \\
\text { Starboard Tiptank } \\
\text { (AlMMS-20) }\end{array}$ \\
\hline Humidity & DLH & $\begin{array}{c}\text { AAF } \\
\text { (NASA } \\
\text { LaRC/ }\end{array}$ & $\begin{array}{l}\text { NASA/ } \\
\text { Diskin }\end{array}$ & $\begin{array}{l}\text { Interior-Uses Optics- } \\
\text { Grade Window Plate }\end{array}$ \\
\hline
\end{tabular}




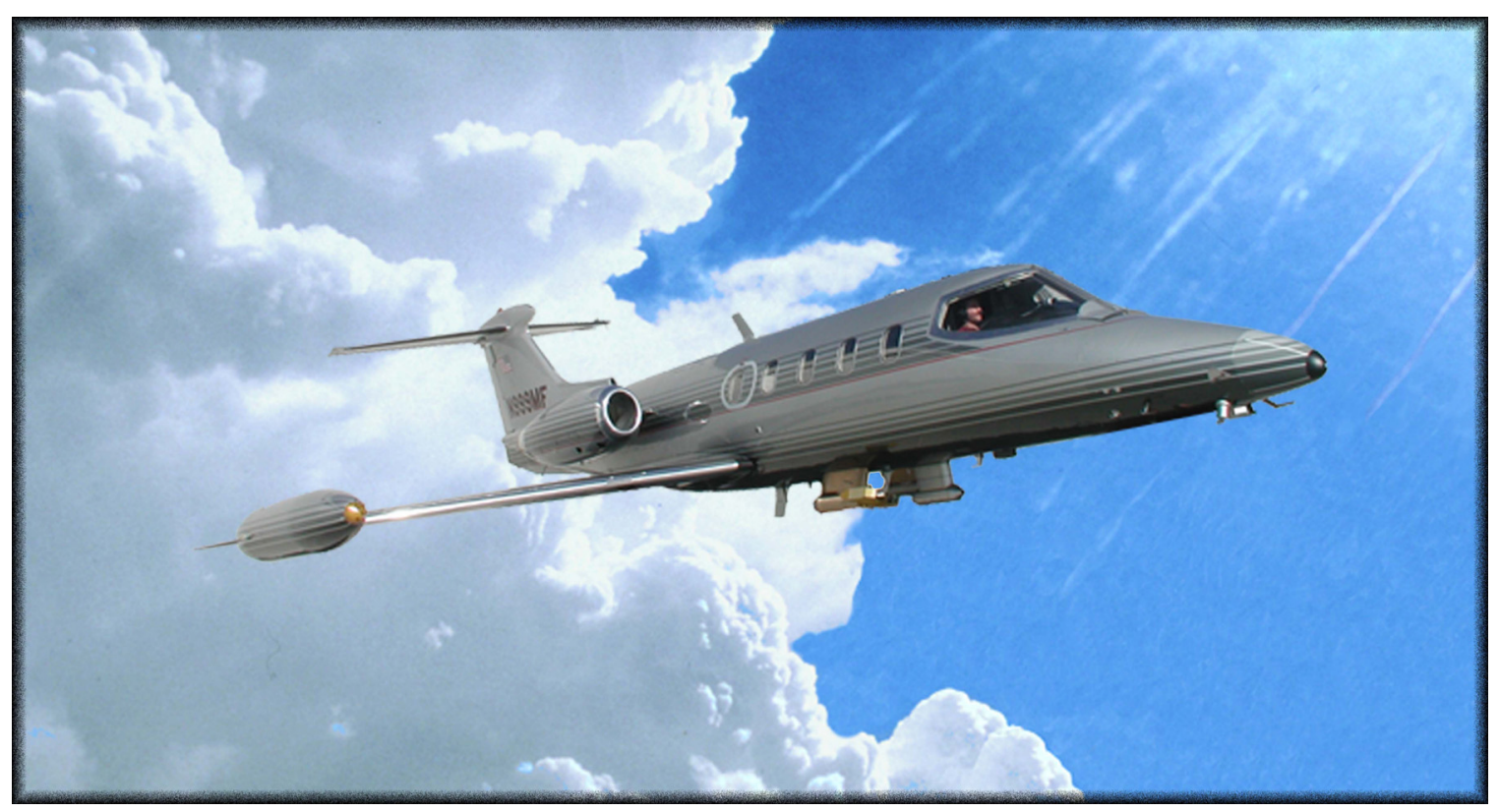

Figure 1. SPEC Learjet.

\subsection{Flight Plans}

The overarching goals of SPARTICUS are to characterize the physical and dynamical properties of middle-latitude cirrus. As outlined above, the experiment has three basic goals. The first of these is to characterize the natural variability of the cirrus particle size distribution in middle-latitude cirrus with a special emphasis on minimizing or eliminating the contribution by shattering artifacts to the counts of small ( $<50$ micron) ice crystals. A second objective of the mission is to provide in situ data for comparison with cloud property retrieval algorithms applied to remote sensing measurements. The validation objective is critical to the eventual scientific utility of ARM and A-Train data, because while aircraft data are detailed and valuable, the data sets created by aircraft are generally unable to fully characterize complex situations specifically or generally in a statistical sense while remote sensors operate continually and, over time, allow for reasonable statistical descriptions. Similarly, a third objective of SPARTICUS is to provide information that would inform development and validation of microphysical and dynamical models of cirrus clouds. For this third objective, coordination of the in situ measurements with remote sensors will add considerably to the value of both data sets. As described in more detail elsewhere in this document, our default mission plan will be to conduct missions over the ARM ground site, over the ship-based remote sensors, over both sites simultaneously, or under the ATrain satellites. The purpose of this section is to provide a set of working plans for implementation of the SPARTICUS aircraft assets to address the various goals of the project. 
Table 2. SPEC Learjet operating characteristics when in research configuration.

\begin{tabular}{|l|l|}
\hline \multicolumn{2}{|c|}{ SPEC Learjet Performance in Research Configuration } \\
\hline Maximum Takeoff Weight & $15,000 \mathrm{lbs}$ \\
\hline Maximum Certificated Ceiling & $45,000 \mathrm{ft}$ \\
\hline $\begin{array}{l}\text { Time to Climb S.L. to FL 370 at Maximum T.O. } \\
\text { Weight @ ISA }\end{array}$ & $20 \mathrm{~min}$ \\
\hline $\begin{array}{l}\text { Maximum Duration (takeoff to touchdown } \\
\text { assuming mission at FL 410) }\end{array}$ & $3 \mathrm{hr}$ \\
\hline Maximum Airspeed & $\begin{array}{l}0.82 \text { Mach } \\
(306 \mathrm{Kts} \text { IAS-approx 450 kts TAS) }\end{array}$ \\
\hline Number of Seats excluding pilots & 5 \\
\hline Electrical Capability & $\begin{array}{l}(2) 400 \mathrm{~A} \text { Generators @ 28.8 VDC = 23 KW } \\
\text { Current Research Power } \\
=7.2 \mathrm{KW} \text { distributed as } \\
5.5 \mathrm{KW} @ 110 \text { VAC 60 Hz } \\
1.7 \mathrm{KW} @ 28 \text { VDC }\end{array}$ \\
\hline
\end{tabular}

\subsection{Experimental Objective 1: Small Particles in Cirrus}

Science Motivation/Hypothesis: The primary goal of this mission objective is to characterize the number of small particles (maximum dimensions less than approximately $50 \mu \mathrm{m}$ ) that occur in cirrus and to determine whether shattering of ice crystals on probe tips significantly influences small particle counts in cirrus.

\section{Measurement Objective:}

- In situ measurements of particle size distributions for deriving extinction optical depth.

- Remotely sensed extinction optical depth from Raman lidar backscatter is critical to this mission objective. Because the Raman lidar measurements are degraded by solar background light, night measurements are necessary.

- Flights could be flown in conjunction with Terra and/or Aqua MODIS, Cloudsat, and Calipso, if possible, for additional comparisons with satellite retrievals or in conjunction with measurements made at the ground-based sites.

\section{General Aircraft Flight Profiles:}

- Option 1: Spirals through the cirrus layer centered on the remote sensing suite at SGP. Optimal configuration would be $5 \mathrm{~km}$ radius with ascent/descent rates of $1000 \mathrm{feet} / \mathrm{minute}$.

- Option 2: Stepped level legs along the wind at various altitudes. Legs should be short $(20 \mathrm{~km})$ for this objective to maximize the coordination with lidar measurements.

\section{Synergy with other missions:}

- Ground-based validation

- A-Train algorithm validation 
- In situ probe inter-comparison

- Cirrus scattering phase functions

Instrument Priority Table (1 Critical, 2 Important, 3 Ancillary)

\begin{tabular}{|c|c|c|c|c|c|c|c|c|c|}
\hline CDP & FSSP & 2DS & PIP & PCASP & CPI & IWC & Turb & DLH & State \\
\hline 1 & 1 & 2 & 3 & 3 & 2 & 2 & 3 & 3 & 3 \\
\hline
\end{tabular}

\subsection{Experimental Objective 2: Ground-based Remote Sensing Validation}

Science Motivation/Hypothesis: Evaluate/verify/inter-compare the retrieval of cloud microphysical properties from ground-based remote sensors with direct in situ measurements of the retrieved quantities. The primary goal of this mission objective is to assess the uncertainty of cloud properties derived from retrieval algorithms (microphysics and radiative) from ground-based remote sensors. Other objectives include the development of empirical relationships (i.e., mass- and area-dimensional relationships in cirrus) that are needed in these algorithms and to characterize the spatial variability of cloud microphysical quantities.

\section{Measurement Objectives:}

In situ microphysics measurements of ice crystal size and shape distributions, bulk measurements such as ice water content and extinction, and water vapor in the vicinity of the ground site.

\section{General Aircraft Flight Profiles:}

- Option 1: In situ aircraft will spiral up/down over ground site (Eulerian) and then fly series of level along-wind legs (approximately $50 \mathrm{~km}$ ) centered on the ground site. Vertical steps would optimally be on the order of $300 \mathrm{~m}$.

- Option 2: If stepped legs are not possible due to FAA restrictions, aircraft could be flown at any altitude in the cloud layer, although measurements would be most valuable in regions of highest IWC or radar reflectivity.

- Option 3: If block altitude is available from FAA, fly spirals continuously with $5 \mathrm{~km}$ radius circles that ascend and descend at $300 \mathrm{~m} / \mathrm{min}$ between cloud base and cloud top, or whatever block altitude is available.

\section{Weather Conditions:}

- Ideally would want to sample cirrus generated from a variety of different formation mechanisms (polar and subtropical jet stream cirrus, anvils, orographic, etc.)

\section{Synergy with other missions:}

- Anvil

- Small particles in cirrus 
- A-Train algorithm validation

- Aging anvil (to be addressed as follow on mission)

Instrument Priority Table (1 Critical, 2 Important, 3 Ancillary)

\begin{tabular}{|c|c|c|c|c|c|c|c|c|c|}
\hline CDP & FSSP & 2DS & PIP & PCASP & CPI & IWC & Turb & DLH & State \\
\hline 1 & 1 & 1 & 1 & 3 & 2 & 1 & 3 & 3 & 3 \\
\hline
\end{tabular}

\subsection{Experimental Objective 3: Cloudsat, CALIPSO, MODIS Validation}

Science Motivation/Hypothesis: The A-Train measurements primarily consisting of the CloudSat radar reflectivity, the CALIPSO lidar backscatter, and the Aqua MODIS radiances and reflectances will be used to derive cloud properties using retrieval algorithms. We have a rare opportunity to create a data set with which these algorithm results can be evaluated.

Measurement Objectives: The primary focus of this exercise will be validation of the retrieval algorithm results. Many of the algorithms being applied to the A-Train data retrieve properties of the cloud layer such as optical depth and ice water path. The only way these layer-mean properties can be adequately validated is by conducting along-track legs and spirals through the cloud layer over a period of time that straddles the satellite overpass.

\section{General Aircraft Flight Profiles:}

- Level Leg Option: Aircraft intersects the CloudSat ground track 15-20 minutes prior to the overpass and flies along the ground track cloud until 5 minutes after the overpass. The aircraft should then double back along the ground track. The aircraft could either fly straight and level at an optimal altitude or porpoise within the cloud. The porpoising should extend over at least $1500 \mathrm{~m}$ (3 CloudSat range resolution volumes). It would be particularly useful for the aircraft to porpoise from the cloudtop region to a thicker portion of the layer in order to validate the cloud detection algorithm.

- Spiral Option: Ideally a reasonably uniform and extensive cirrus field would be targeted. The aircraft would plan to be midway through a spiral descent as the satellite passes over the aircraft. Ideally the aircraft would have completed a spiral up through the layer prior to the overpass so as to document any variability in the cloud layer.

Synergy with other missions: This objective should only take up approximately 1 hour of flight time and can therefore be combined with other objectives as appropriate.

Instrument Priority Table (1 Critical, 2 Important, 3 Ancillary)

\begin{tabular}{|c|c|c|c|c|c|c|c|c|c|}
\hline CDP & FSSP & 2DS & PIP & PCASP & CPI & IWC & Turb & DLH & State \\
\hline 2 & 2 & 1 & 2 & 3 & 1 & 1 & 3 & 3 & 3 \\
\hline
\end{tabular}




\subsection{Experimental Objective 4: Cirrus Evolution}

Science Motivation/Hypothesis: Do aged cirrus (cirrus not directly associated with convective outflow) continue to evolve through their life cycle, or do they reach a steady state where perhaps radiative destabilization and supply of water vapor from below are balanced by crystal sedimentation? Understanding the processes governing this evolution is important for model validation and parameterization development. It is the goal of this objective to try to document specific aspects of the cloud field and its local environment that will assist in future modeling efforts of cirrus.

Measurement Objectives: If we assume that the cloud field is in an approximate steady-state condition, then we should be able to balance the upward flux of water vapor with the loss of condensate in the lower portions of the cloud. Our goal is to document these components of the water budget. Using the water vapor and turbulence probes on the Lear, one would ideally like to calculate the three-dimensional flux convergence of water $\left(\nabla \bullet \vec{V}^{\prime} q^{\prime}\right)$ into the cloud field. However, while documentation of the horizontal convergence of water vapor can be attempted by flying at constant altitude over a closed geographic region, the vertical flux convergence $\frac{\partial}{\partial z}\left(w^{\prime} q^{\prime}\right)$ would likely be more obtainable from aircraft by conducting large (radius 10-20 km) slow spirals from several kilometers below cloud base into the middle portion of the cloud layer.

Ground-based remote sensing data suggest that the IWC reaches a maximum in the middle third of the cirrus layer and then decreases toward cloud base. This decrease toward cloud base is likely due to sublimation of ice crystals. Documenting this process will require coordination between the in situ aircraft and ground-based remote sensors. Because the cloud will contain substantial spatial variability, it is unlikely that in situ aircraft alone can address the sedimentation rate.

The in situ measurements can supply important Z-IWC, D-Mass, and D-Area empirical relationships that will allow for accurate and targeted retrievals with the remote sensing measurements.

\section{General Aircraft Flight Profiles:}

- In characterizing the water budget, it is important that the aircraft obtain the most accurate statistics possible on the horizontal and vertical wind so that gradients can be calculated (assuming a steadystate situation). Beginning several kilometers below cloud base, fly a box pattern approximately 20 $\mathrm{km}$ on a side, where wings are straight and level during the entire $20 \mathrm{~km}$ section. After completion of each box, step upward 1000 feet and repeat until a predetermined altitude within the cloud layer is reached.

- Once the middle section of the cloud is reached, begin a series of stepped race tracks. Step the racetrack vertically upward through the cloud layer, followed by a Lagrangian spiral once the cloud top or the maximum altitude is reached. Repeat the pattern while fuel and cloud allow, reorienting the pattern with the motion of the cloud field.

- Ideally, this mission would be flown in conjunction with the ground site. 


\section{Weather Conditions:}

- The cirrus field examined should be extensive and persistent and unchanging (a rare event). Optimally, no intervening clouds should block view of the layer from the ground-based lidar if conducted in the vicinity of the ground site.

\section{Synergy with other missions:}

- Ground-based validation

- Small particles in cirrus

- A-Train algorithm validation

Instrument Priority Table (1 Critical, 2 Important, 3 Ancillary)

\begin{tabular}{|c|c|c|c|c|c|c|c|c|c|}
\hline CDP & FSSP & 2DS & PIP & PCASP & CPI & IWC & Turb & DLH & State \\
\hline 2 & 1 & 1 & 2 & 1 & 1 & 1 & 1 & 1 & 1 \\
\hline
\end{tabular}

\subsection{Experimental Objective 5: Anvil Evolution}

Science Motivation/Hypothesis: Of particular interest is the evolution of deep convective outflow into self-maintaining cirrus layers. Understanding the processes governing this evolution is important for model validation and parameterization development. Understanding the evolution of particle habits from those typical of ejecta from updrafts to more pristine forms is important for development of remote sensing algorithms. The specific science questions we seek to address with this objective are: (1) How do anvil cirrus evolve after detrainment from a cumulus tower, and (2) What are the physical mechanisms that govern this process? A primary goal of this objective will be to document, with combined in situ and remote sensing data, aspects of the condensed water budget in the cloud system as it evolves.

Measurement Objectives: To address the questions posed above it is necessary to characterize the change in cloud microphysical properties of anvil outflow as it evolves over time/distance away from a convective source. The mission will require both in situ measurements and will be most valuable when combined with remote sensing.

- The key measurements are in situ microphysics, dynamics, and thermodynamics, particularly size distribution, IWC, extinction/integrated cross sectional area, vertical motion and turbulence, water vapor.

- This mission should be flown in conjunction with ground-site measurements if possible. The ideal situation would be convection upstream of ARM causing an anvil spreading over the ground site as the aircraft advect with the evolving cloud field.

\section{General Aircraft Flight Profiles:}

- Option 1: Aircraft chooses an altitude within the anvil outflow as close to the convective source as deemed safe by the air crew and initiates a crosswind racetrack $50 \mathrm{~nm}$ across the wind and $20 \mathrm{~nm}$ along the wind. During the downwind leg of the racetrack, the aircraft should ramp down several thousand feet and fly the next across-wind leg at a lower altitude. During the upwind leg the in situ 
aircraft should climb back to the original altitude before performing the next crosswind leg. The racetrack will shift laterally with the mean wind. Orienting the in situ aircraft across the wind and stepping the racetrack along the wind will allow for documentation of the change of cloud properties with time.

- Option 2: In situ aircraft conducts a series of spiral ascent and descents within the cloud systempreferably over the ground site. The spirals could step downwind to examine evolution with time.

- Option 3: Options 1 and 2 flown in conjunction with A-Train. In this circumstance A-Train would provide a single cross-section at some point during the time the aircraft is translating with the evolving anvil. GOES satellite imagery would be relied on for additional data.

\section{Weather Conditions:}

- Ideal situation would follow an anvil system from its inception in deep convection through a portion of its life cycle as the anvil passed over the ground sites while the A-Train loiters overhead.

\section{Synergy with other objectives:}

- Ground-based validation

- Small particles in anvils

With the exception of the ground-based validation objective, this mission should be the primary focus of an entire flight or a substantial portion of an entire flight if it is to be successful.

Instrument Priority Table: (1 Critical, 2 Important, 3 Ancillary)

\begin{tabular}{|c|c|c|c|c|c|c|c|c|c|}
\hline CDP & FSSP & 2DS & PIP & PCASP & CPI & IWC & Turb & DLH & State \\
\hline 2 & 1 & 1 & 2 & 1 & 1 & 1 & 1 & 1 & 1 \\
\hline
\end{tabular}

\subsection{Operational Considerations}

The SPARTICUS deployment will run over several months. Therefore, it is not practical for the scientists to devote full time to flight operations in the field. Our plan is to have weather briefings, flight planning, and decision-making occur remotely, with the scientists predominantly staying at their home institutions. Web meeting tools will be used such that all participants can view and discuss forecast products and satellite imagery. To avoid an excess workload for any individual on the science team, we will have rotating teams of two scientists responsible for day-to-day decision-making, with one of these scientists taking the lead. With eight investigators on the science team, this plan should prevent fatigue over the long deployment duration. During the first week or two, everybody on the science team will be encouraged to participate, such that we all have a clear idea of the criteria for decision making.

The region of operations is defined by two 400 NM circles; one centered over Rocky Mountain Metropolitan Airport (formerly "JeffCo"), the other centered over the SGP site (Figure 2). We will place a strong emphasis on our primary target, which is cirrus over the SGP site. Secondary priority will be given to sampling cirrus coordinated in space and time with the A-Train overpasses. We will keep careful track of our monthly flight hour burn rate. If we find that we are not using our allotted hours rapidly 
enough with the primary and secondary targets, we will broaden our approach and sample cirrus within the operations area even if it is well away from the SGP site or the A-Train overpasses. This latter approach may be useful late in the deployment for sampling types of cirrus that have not been encountered with our primary targets.

It is well known that cirrus are transient phenomena. A common situation we will encounter is that the cirrus over the SGP site have either moved away from the site or dissipated. When this occurs, the pilot will need to decide whether cirrus within range but away from the SGP site can be sampled, or whether returning to base is appropriate.

We will occasionally want to sample liquid clouds to evaluate instrument performance. The liquid-cloud sampling runs can be brief (10 $\mathrm{min})$ and can hopefully be obtained by ascent or descent from an airport (such as after refueling in the SGP area). One liquid-cloud sampling run per month should be sufficient.

It will be critical to the SPARTICUS mission to have reliable information regarding the status of instruments at the SGP site. In particular, the MMCR, MPL, and Raman lidar are critical. Information regarding these instruments should be part of each briefing. Ideally plots in as near real-time as possible from the MPL and MMCR should be available on the internet for planning purposes - especially during the morning decision-making process.

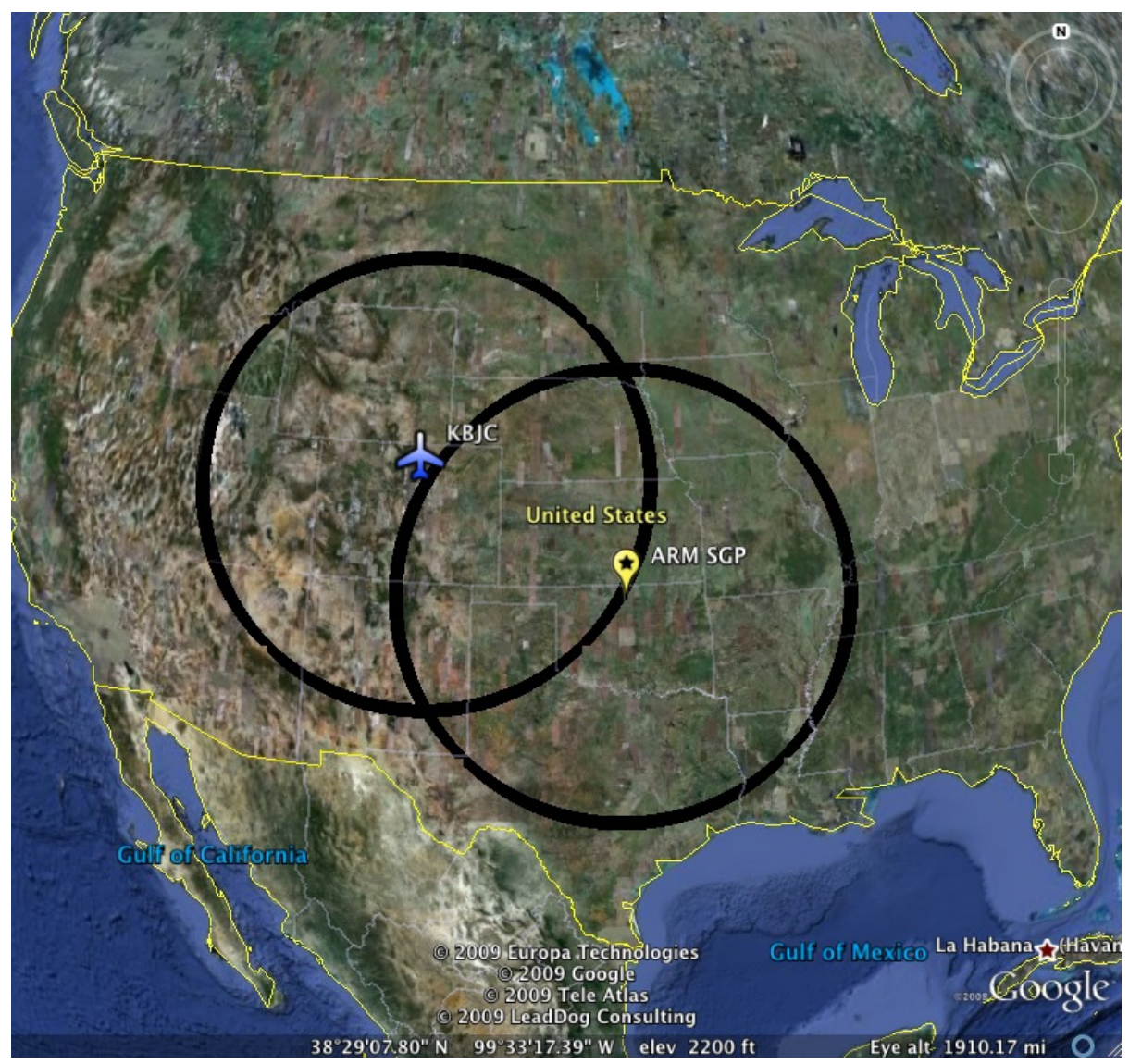

Figure 2. Flight operations area includes two 400-nautical-mile circles centered around Boulder, Colorado, and the ARM SGP site near Lamont, Oklahoma. 


\subsection{Daily Operations}

On a day for which we have decided that a flight is likely, we will have a weather briefing $\sim 2.5$ to 3 hours before the scheduled takeoff time. This briefing will be focused on the forecast for cirrus occurrence at the target locations on that day. Shortly after this briefing, a go/no-go decision for the day's flight will be made, and the takeoff time will be set. At least in the early stages of the deployment, the go/no-go decision will depend on the following criteria:

- Likelihood of cirrus at the primary or secondary targets based on the latest meteorological information.

- No significant icing conditions at the level of operations.

- Severe weather near takeoff or landing times, or in the vicinity of the operations area.

- Too many critical instruments are down (see critical instrument ranking under "Flight Plans").

After the initial preflight teleconference, a second weather briefing will occur that will focus on the weather outlook for the next few days and longer-term forecast. Shortly after this briefing, the two mission scientists on duty will decide whether to stand up for a flight the following day, and a preliminary flight plan will be determined and communicated to the pilot by the AAF representative. Flight debriefs will only occur if the principal investigator (PI)/co-investigator determines it is necessary. Otherwise, debriefs will be provided in the pilot notes on the wiki page, and questions by the science team can be asked during the morning pre-brief. A typical flight day schedule with a takeoff time of 1200 Mountain Time is described in Table 3.

Table 3. Sample flight day for typical cirrus flight plan over the SGP site. All times are in Mountain Time.

\begin{tabular}{|c|c|}
\hline Time & Activity \\
\hline 0930 & $\begin{array}{l}\text { *Pre-flight weather brief to determine timing of cirrus over SGP; technician already on site at } \\
\text { hangar }\end{array}$ \\
\hline 1000 & $\begin{array}{l}\text { - Decision to fly; flight crew leaves domicile for hangar; technician begins to prepare } \\
\text { payload and aircraft for flight } \\
\text { - *Short-term forecast and weather outlook briefing begins }\end{array}$ \\
\hline 1030 & Crew arrives at hangar \\
\hline 1200 & Takeoff \\
\hline 1300 & Aircraft arrives on site over SGP; samples cirrus layer at several altitudes \\
\hline 1500 & Aircraft lands in Ponca City, Oklahoma for refueling \\
\hline 1600 & Takeoff from Ponca City, Oklahoma; continue to sample \\
\hline 1800 & Begin ferry back to Boulder, Colorado \\
\hline 1900 & Land in Boulder, Colorado \\
\hline 2000 & Crew arrives at domicile \\
\hline $10 \mathrm{hrs}$. & Total flight time for crew. \\
\hline \multicolumn{2}{|c|}{$\begin{array}{l}\text { *Weather briefings: A forecaster located at the SGP site in Oklahoma will conduct the weather briefings. } \\
\text { The briefings will be held via teleconference and web-conferencing tools and will be attended by an AAF } \\
\text { representative, flight team representative, forecaster, and two members of the scientific steering } \\
\text { committee. The pre-flight brief will focus on that day's flight; the } 1000 \text { briefing will focus on the extended } \\
\text { forecast. The forecaster will utilize state-of-the-art forecast models and visualization tools developed by } \\
\text { the National Oceanic and Atmospheric Administration (NOAA). }\end{array}$} \\
\hline
\end{tabular}


The takeoff time for daytime flights will typically be around 1200 Mountain Time, allowing time for a second local flight over the SGP site after refueling at Ponca City airport. The decision of whether or not a second flight is warranted will (at least early in the deployment) depend on the persistence of cirrus over the SGP site. The pilot will consult with the mission scientists to make this decision.

When conducting missions in the vicinity of the SGP ground site, it will be necessary for an individual to be present at the ground site who can interact with the flight crew via radio or cell phone. Information regarding the base, top, and coarse structure of the cirrus layer will need to be relayed periodically to the aircraft. The individual on the ground will need to be able to interpret raw imagery from either the micropulse lidar or the MMCR.

Nighttime over-flights of the Raman lidar are considered to be "mission-critical" to help characterize extinction and water vapor mixing ratio measurements. Ideally, these flights will occur toward the end of a scheduled flight for $\sim 1$ hour near or after sunset. Night flights should be a routine aspect of the mission and occur as often as possible, weather permitting.

\subsection{Pilot Duty Day}

Pilots must adhere to the following FAA guidelines to ensure proper duty times under Federal Aviation Regulations Code 135:

- A flight day consists of the time between when they leave and return from their hotel room or domicile.

- If the flight day exceeds 10 hours, they must rest for at least 14 hours before they can resume operations.

\subsection{Personnel Responsibilities}

AAF Representative:

- Makes the final go/no-go call based on scientific recommendation and safety considerations

- Communicates with aircraft team any concerns or suggestions from the science team

- Verifies flight-day summaries and wiki content (real-time data plots, QC plots, etc.)

- Tracks flight time available and keeps record on wiki site

- Supervises the timely availability of data and quicklook plots

Aircraft Team Representative:

- Attends flight pre-briefing calls to report conditions of instruments and aircraft personnel

- Reports go/no-go decision to pilot

- Uploads data to IOP-Share ftp site 
Steering Committee PI:

- Provides scientific recommendation for flight plan and go/no-go decision

- Reviews flight debrief information and makes scientific recommendations to flight plans or data collection strategy

Steering Committee second-in-command:

- Confers with PI on go/no-go decisions and flight plans

- Serves as PI if PI cannot assume responsibilities

SGP surface meteorologist

- Serves as cloud spotter, describing current SGP conditions

- Provides a nowcast of the cloud conditions based on the synoptic state on flight days

- Provides short-term forecast and long-term outlook using model analysis

- Provides quicklooks to the teleconference participants (via the wiki) and reports ground-based instrument readiness

- Posts brief weather statement on wiki page

- Posts brief status of critical surface instruments

\subsection{Data Evaluation}

Data evaluation will be performed on a daily basis after each flight. A representative from the aircraft team must upload flight data to the ARM IOP-Share archive within 24 hours after a flight from the aircraft team. At that time, quicklook plots will be auto-generated and posted on the SPARTICUS wiki site. It is the responsibility of the instrument mentor to perform QC checks on the data within 1 week of each flight to ensure quality data throughout the experiment and report any issues on the wiki site. The SPARTICUS steering committee will also examine the quicklook plots to help identify data issues and to ensure that data needs are met that will help fulfill the mission science objectives. Any problems with the data will be recorded in the comments section on the wiki site.

\subsection{Data Dissemination}

The final data set will be submitted to the ARM Data Archive by the instrument PIs within 6 months of the end of the experiment. AAF will create a public website where flight summaries, quicklooks, data quality reports, images, etc. will be posted for the general public. 


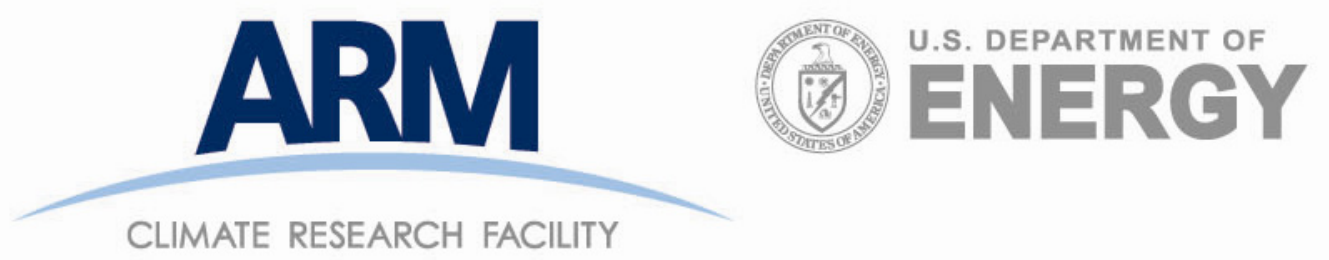

wWw.arm.gov 